\title{
1 Determination of ferrous and total iron in refractory spinels
}

2 J.E. Amonette ${ }^{a, *}$ and J. Matyáś ${ }^{b}$

$3 \quad{ }^{a}$ Physical Sciences Division, Pacific Northwest National Laboratory, Richland, WA 99352 USA

$4 \quad{ }^{\mathrm{b}}$ Material Science Department, Pacific Northwest National Laboratory, Richland, WA 99352 USA ABSTRACT

7 challenge due to their refractory nature. The resultant extreme conditions needed to obtain complete

8 dissolution generally oxidize some of the Fe(II) initially present and thus prevent the use of colorimetric

9 methods for Fe(II) measurements. To overcome this challenge we developed a hybrid

oxidimetric/colorimetric approach, using $\mathrm{Ag}(\mathrm{I})$ as the oxidimetric reagent for determination of $\mathrm{Fe}(\mathrm{II})$ and

11 1,10-phenanthroline as the colorimetric reagent for determination of total Fe. This approach, which

12 allows determination of Fe(II) and total Fe on the same sample, was tested on a series of four

13 geochemical reference materials and then applied to the analysis of $\mathrm{Fe}(\mathrm{Ni})$ spinel crystals isolated from

14 simulated high-level-waste (HLW) glass and of several reagent magnetites. Results for the reference

15 materials were in excellent agreement with published values, with the exception of USGS BIR-1, for

16 which higher Fe(II) values and lower total Fe values were obtained. The Fe(Ni) spinels showed Fe(II)

17 values at the detection limit (ca. 0.03 wt\% Fe) and total Fe values higher than obtained by ICP-AES

18 analysis after decomposition by lithium metaborate/tetraborate fusion. For the magnetite samples,

19 total Fe values were in agreement with reference results, but a wide range in Fe(II) values was obtained 20 indicating various degrees of conversion to maghemite. Formal comparisons of accuracy and precision 21 were made with 13 existing methods. Accuracy for Fe(II) and total Fe was at or near the top of the 
22 group. Precision varied with the parameter used to measure it but was generally in the middle to upper 23 part of the group for Fe(II) whilethat for total Fe ranged from the bottom of the group to near the top.

Keywords: ferrous iron; spinel; 1,10-phenanthroline; nickel; hydrofluoric acid; silver; potentiometry; 25 ferrous ethylenediammonium sulfate; ferrous ammonium sulfate, potassium bromide

\section{$27 \quad 1.0$ Introduction}

28 Quantitative determination of ferrous iron [Fe(II)] in minerals and related solid materials represents one 29 of the most challenging procedures in analytical chemistry. Despite recent advances in and improved 30 availability of spectroscopic methods such as Mössbauer and X-ray absorption near-edge (XANES), the 31 majority of $\mathrm{Fe}(\mathrm{II})$ determinations continue to be made using wet-chemical methods due to their better 32 precision, lower detection limits, and lower cost.

33 The chief difficulty in wet-chemical analysis arises from maintaining the Fe(II) titer during digestion and 34 before its assay, whether by oxidimetry or colorimetry. Both of these approaches have a rich literature 35 (see reviews by Schafer, 1966; Amonette et al., 1994) and many methods have been developed, 36 principally for non-refractory minerals. Maintenance of the Fe(II) titer is made significantly more 37 difficult when the material is refractory, due to the extreme conditions (high temperature, long 38 duration, reagents) typically required to dissolve these materials. This is certainly the situation for Fe39 bearing spinels, a common crystalline phase precipitating from high-level waste (HLW) glasses (Matyáš 40 et al. 2010). The spinel crystals do not affect the long-term durability of the glass; however, they settle 41 and accumulate in the riser of the melter due to their high density and large size (up to $500 \mu \mathrm{m}$ ) and can 42 potentially block the discharge of the molten glass into canisters (Matyáš et al. 2011, 2015). Since redox 
43 state of the Fe plays an important role in their formation and growth there is a need to develop a fast

44 and reliable analytical method to measure Fe(II) and Fe(III) in these materials.

45 As determination of mean Fe oxidation state is usually the parameter of interest, a value for Fe(II) must

46 be balanced by one for Fe(III), which is usually obtained by subtraction of the Fe(II) value from that

47 obtained for total Fe on a separate sample analyzed by other methods optimized for total elemental

48 analysis. With the development of colorimetric methods for determination of total Fe in aqueous

49 solutions that rely on complexation of Fe(II) by a chromophore such as 1,10-orthophenanthroline (phen)

50 have come several methods for non-refractory minerals that allow determination of Fe(II) and total Fe

51 on the same sample digest (Begheijn, 1979; Stucki, 1981; Komadel and Stucki, 1988, Amonette and

52 Templeton, 1998, Husler et al., 2011; Tarafder and Thakur, 2013). One fusion-decomposition method

53 suitable for refractory minerals (Ayranci, 1992) has also been developed but requires a special apparatus

54 and Pt/Au crucibles. These Fe(II)/total Fe methods are of great value where sample quantities are

55 limited, and offer better estimates of the $\mathrm{Fe}(\mathrm{II}) / \mathrm{Fe}(\mathrm{III})$ ratio by avoiding sample to sample variability.

56 At the same time, however, methods that rely on oxidimetry (e.g., Wilson 1955; Ungethüm, 1965;

57 Amonette and Scott, 1991), that is, the change in quantity of an aqueous oxidant present during the

58 decomposition of the sample, offer generally better precision and lower detection limits than those

59 based on colorimetry. The strength of these methods often rests on the stability of the oxidant during

60 the digestion, and as a result a temperature limit may be encountered or a specific mixture of acids may

61 be required which, in turn, constrains the methods to non-refractory samples.

62 In the present work, we set out to explore possible ways of determining Fe(II) and total Fe in refractory

63 Fe spinels, some of which (i.e., the spinel crystals isolated from the HLW glass) also contained Ni and Cr.

64 Analysis of representative samples by Mössbauer spectroscopy suggested that the Fe(II) contents were 65 below detection by that technique, and thus a wet-chemical approach was needed. As sample 
quantities were limited, a method that combined these two analyses on a single sample was desired.

67 We started by modifying a colorimetric method (Amonette and Templeton, 1998) and then, based on

68 the results, proceeded to develop a hybrid method that used oxidimetry for Fe(II) and colorimetry for

69 total Fe. To our knowledge, this is the first method that combines oxidimetry and colorimetry for

70 analysis of Fe(II) and total Fe in minerals and related Fe-bearing materials, whether refractory or not.

\section{$71 \quad 2.0$ Materials and Methods}

\section{$72 \quad 2.1$ Samples and Standards}

73 A set of four geochemical reference materials, as well as several iron reagents, were tested. The 74 reference materials were a granite (G-2) and a basalt (BIR-1) from the U.S. Geological Survey, and two 75 magnetite ores (OREAS 700 and OREAS 701) from Ore Research \& Exploration Pty., Ltd., Victoria, 76 Australia. The iron reagents were two high-purity magnetites (Alfa-Aesar 12962, Aldrich 518158), a 77 nano-sized magnetite powder (Aldrich 637106), and an in-house-synthesized magnetite. This magnetite 78 was prepared following the method of Schwertmann and Cornell (2000), with the slight modification of 79 treating the starting $\mathrm{FeSO}_{4}$ solution with a suspension of zerovalent Fe for one month to ensure 80 complete reduction of any $\mathrm{Fe}(\mathrm{III})$ that may have been present. Subsequent oxidation of the $\mathrm{FeSO}_{4}$ in an 81 alkaline solution of $\mathrm{KNO}_{3}$ at $90^{\circ} \mathrm{C}$ under a $\mathrm{N}_{2}$ atmosphere yielded the magnetite particles, which were 82 dried and stored under $\mathrm{N}_{2}$ until analysis. In addition to these reference materials, $\mathrm{Fe}(\mathrm{Ni})$ spinel crystals 83 isolated from simulated waste glass samples were analyzed. Salient properties of the reference 84 materials and samples are listed in Table 1.

\section{$85 \quad 2.2$ Chemical Reagents}

86 Hydrofluoric acid (HF, 48\%, Sigma-Aldrich 30107), sulfuric acid $\left(\mathrm{H}_{2} \mathrm{SO}_{4}, 99.999 \%\right.$, Aldrich 339741), silver 87 fluoride (AgF, Aldrich 226858), potassium bromide ( $\mathrm{KBr}$, Aldrich 378844), boric acid $\left(\mathrm{H}_{3} \mathrm{BO}_{3}\right.$, Sigma88 Aldrich B0394), hydroxylamine sulfate $\left(\left(\mathrm{NH}_{2} \mathrm{OH}\right)_{2}-\mathrm{H}_{2} \mathrm{SO}_{4}\right.$, Aldrich 210250), ferrous ammonium sulfate 
hexahydrate $\left(\mathrm{Fe}\left(\mathrm{NH}_{4}\right)_{2}\left(\mathrm{SO}_{4}\right)_{2} \cdot 6 \mathrm{H}_{2} \mathrm{O}\right.$, FAS, $99.997 \%$ trace metals content, Aldrich, 203505) and trisodium citrate dihydrate (Sigma-Aldrich S4641) were used as received after dilution or dissolution in deionized water (as appropriate). A $1 \%$ or $10 \%$ solution of the analytical reagent for total Fe, 1,10orthophenanthroline (phen, Aldrich 131377) was prepared in technical-grade ethanol $\left(\mathrm{C}_{2} \mathrm{H}_{5} \mathrm{OH}, 95 \%\right)$

93 before being mixed with the aqueous reagents.

94 Table 1. Nominal compositions of reference materials and reagents analyzed.

\begin{tabular}{|c|c|c|c|c|}
\hline \multirow[t]{3}{*}{ Name } & \multirow[t]{3}{*}{ Description } & \multirow[t]{3}{*}{ Source } & \multicolumn{2}{|c|}{ Nominal Composition } \\
\hline & & & $\mathrm{Fe}^{2+}$ & Total Fe \\
\hline & & & \multicolumn{2}{|c|}{------- weight \% ------ } \\
\hline G-2 & $\begin{array}{l}\text { Rhode Island granite } \\
\text { (Split 100-7) }\end{array}$ & $U_{S G S}^{a}$ & 1.13 & 1.86 \\
\hline BIR-1 & $\begin{array}{l}\text { Icelandic basalt } \\
\text { (Split 396) }\end{array}$ & USGS & 6.51 & 7.87 \\
\hline OREAS 700 & Magnetite ore & OREAS $^{b}$ & 9.38 & 15.57 \\
\hline OREAS 701 & High Grade Magnetite ore & OREAS & 13.49 & 23.02 \\
\hline ALP & $\begin{array}{c}\text { Reagent Magnetite } \\
\text { (Product 518158, Lot MKBJ5645V, } \\
99.99 \% \text { metal purity) }\end{array}$ & Aldrich $^{c}$ & $(23.93)^{f}$ & 71.8 \\
\hline ALNano & $\begin{array}{c}\text { Nanosized Reagent Magnetite } \\
\text { (Product 637106, Lot MKBD8421V, 97\% } \\
\text { metal purity, 50-100 nm particle size) }\end{array}$ & Aldrich $^{c}$ & $(22.40)^{f}$ & 67.2 \\
\hline AAP & $\begin{array}{c}\text { Reagent Magnetite } \\
\text { (Product 12962, Lot 22044, 99.997\% } \\
\text { metal purity) }\end{array}$ & Alfa Aesar ${ }^{d}$ & $(24.10)^{f}$ & 72.3 \\
\hline $\mathrm{OQ}$ & $\begin{array}{l}\text { Magnetite Synthesized In-House } \\
\text { (Odeta Qafoku, BNW60373:71) }\end{array}$ & $\mathrm{PNNL}^{\mathrm{e}}$ & $(24.12)^{g}$ & $(72.36)^{g}$ \\
\hline
\end{tabular}

${ }^{\mathrm{a}}$ United States Geological Survey, Denver, CO, USA

97 'Sigma-Aldrich Chemical Co., St. Louis, MO, USA

98 dAlfa Aesar, Ward Hill, MA, USA

${ }^{\mathrm{e}}$ Pacific Northwest National Laboratory, Richland, WA, USA

f Stoichiometric estimate for magnetite based on Total Fe value provided by manufacturer ${ }^{g}$ Stoichiometric estimate for magnetite assuming $100 \%$ purity 


\subsection{Apparatus and Instrumentation}

104 Samples were digested in translucent 7-ml polyfluoroallomer (PFA) vials with gas-tight caps (Savillex, 105 Eden Prairie, MN, No. 200-007-20). Vials were incubated in the dark in a sand bath that was heated to $98^{\circ} \mathrm{C}$ and located inside a $\mathrm{N}_{2}$-atmosphere filled chamber. Heat was maintained by a heat tape wrapped around the sand bath and controlled by a thermostatted power supply. Digests were diluted in a 125$\mathrm{mL}$ titration vessel made from the bottom half of a $250-\mathrm{mL}$ high-density polyethylene (HDPE) bottle. Subsamples were diluted in 15 - or 50-mL polypropylene centrifuge tubes (total Fe) and 30-mL amber HDPE bottles. Absorbance readings were obtained using disposable plastic cuvettes and a Shimadzu UV2501PC spectrophotometer.

\subsection{Analytical Procedures}

Two analytical procedures were tested. The first was a modification of the colorimetric method of Amonette and Templeton (1998) in which both ferrous and total Fe were determined using complexation with phen. The second procedure combined an argentometric method for determination of ferrous Fe, modified from that of Ungethüm (1965), with the colorimetric approach of Amonette and Templeton (1988) for determination of total Fe.

Colorimetric Procedure: The modified colorimetric method, an early version of which was described in Matyáš et al. (2013), involved digesting $40 \mathrm{mg}$ of spinel in $6 \mathrm{~mL}$ of $\mathrm{N}_{2}$-sparged $48 \% \mathrm{HF}$ for periods of $48 \mathrm{~h}$ or longer. This period of time was determined based on preliminary work that showed that digestion was incomplete at shorter times. After incubation, samples were cooled and weighed outside the chamber, then returned to the chamber where they were transferred quantitatively to $125-\mathrm{mL}$ amber bottles and diluted with a $\mathrm{N}_{2}$-sparged solution containing $12 \mathrm{~mL}$ of $10 \% \mathrm{H}_{2} \mathrm{SO}_{4}, 60 \mathrm{~mL}$ of $5 \% \mathrm{H}_{3} \mathrm{BO}_{3}, 2 \mathrm{~mL}$ of a $10 \%$ solution of phen in $95 \%$ ethanol, and $34 \mathrm{~mL}$ of deionized water. Two $0.5-\mathrm{ml}$ aliquots of this 
solution were used to rinse the digestion vials, bringing the final volume of the diluted digestate to 115 $\mathrm{mL}$. After dilution, the ferrous Fe concentration was stable and could be stored for several weeks if necessary.

128 To determine the concentrations of ferrous and total Fe in the diluted digestates, two further dilutions 129 were made. One-ml aliquots of the diluted digestate were placed in separate $15-\mathrm{ml}$ amber bottles, and 130 diluted either with $9 \mathrm{ml}$ of $1 \%$ trisodium citrate (for ferrous Fe determination) or $9 \mathrm{~mL}$ of a $1 \%$ trisodium 131 citrate- $1 \% \mathrm{NH}_{2} \mathrm{OH}$ solution (for total Fe determination). An aliquot of the ferrous Fe analyte was placed 132 in a cuvette and the absorbance at $510 \mathrm{~nm}$ measured immediately. Absorbance of the total-Fe 133 analyzate was determined a minimum of 90 minutes after its preparation. A series of FAS standards, 134 ranging from 0 to $70 \mathrm{mg}$ of sample, were also carried through the procedure and used to calibrate the 135 method.

Oxidimetric Procedure: An argentometric method with potentiometric determination based on that of 137 Ungethüm (1965) was used with several significant modifications. Notably, during digestion and 138 titration the samples are kept in the dark, or at very low light levels to minimize possible artifacts due to 139 photoreduction, the spinel samples are pre-ground under acetone to facilitate decomposition, the 140 digestion period is on the order of 48 hours (and can be longer if needed), and the contents of each vial 141 are titrated immediately after dilution to minimize reoxidation of $\mathrm{Ag}(\mathrm{m})$. Further, an aliquot of the 142 digestate is taken prior to titration for determination of total Fe by colorimetry. Finally, because of 143 interferences in the dissolved $\mathrm{Ag}(\mathrm{I})$ titer caused by sulfate ions present in the two common $\mathrm{Fe}(\mathrm{II})$ 144 standards (FAS, and ferrous ethylenediammonium sulfate), $\mathrm{KBr}$ is used as the primary standard for 145 measuring the titer of the initial AgF solution, as well as that of the digested sample. A total Fe standard 146 is still needed, however. A flow chart for the method is given in Fig. 1 and a detailed description follows. 
Sample preparation: With most spinels, sample comminution is required to ensure complete

$\mathrm{Fe}(I I)$ Analysis: In the steps described in the following paragraph, work quickly and under reduced lighting conditions to decrease the potential for alteration of the $\mathrm{Ag}(\mathrm{I})$ titer either by photoreduction or reoxidation by the diluted digestate. Remove the vial from the opaque container and weigh it. Transfer the digest quantitatively to a tared 125-mL HDPE titration vessel using a total of $36 \mathrm{~mL}$ of $\mathrm{H}_{2} \mathrm{O}$. Reweigh the titration vessel. Tare a $15-$ to $50-\mathrm{ml}$ polypropylene test tube and cap, add $10 \mathrm{~mL}$ of a $0.16 \mathrm{M} \mathrm{(1 \% )} \mathrm{H}_{3} \mathrm{BO}_{3}-1 \% \mathrm{NH}_{2} \mathrm{OH}$ solution, and reweigh. Using a calibrated pipet, transfer $1 \mathrm{ml}$ of the diluted digestate into the test tube, add cap, and then record the weight. This solution is termed the total-Fe reductate. Add a stir-bar to the titration vessel containing the remainder of the 
diluted digestate and insert a combination Ag+-ion selective electrode. Titrate, while stirring, with $0.0200 \mathrm{M} \mathrm{KBr}$, using a $10-\mathrm{mL}$ Class $\mathrm{A}$ buret, until the endpoint (ca. $200 \mathrm{mV}$ relative to a standard $\mathrm{H}_{2}$ electrode) is reached. Record the titrant volume.

Total Fe determination: Let the total-Fe reductate sit for 8 hours, preferably overnight, to reduce 174 the remaining $\mathrm{Ag}(\mathrm{I})$. Tare a second $15-$ to $50-\mathrm{ml}$ polypropylene test tube and cap, add 10-mL of a $1751 \% \mathrm{Na}_{3}$-citrate, $1 \mathrm{mM} \mathrm{1,10-orthophenanthroline} \mathrm{solution} \mathrm{and} \mathrm{reweigh.} \mathrm{Using} \mathrm{a} \mathrm{calibrated} \mathrm{pipet} \mathrm{add}$ $176 \quad 1-2 \mathrm{~mL}$ (depending on expected Fe content) of the total-Fe reductate to the vial and reweigh. After 17790 minutes, measure the absorbance at $510 \mathrm{~nm}$.

$178 \quad$ Blanks and Standards: Reagent-grade $\mathrm{KBr}$ is sufficiently stable that, after drying for 2 hours at $179 \quad 110^{\circ} \mathrm{C}$ followed by cooling to room temperature in a desiccator, it can serve as a primary standard. 180 If additional calibration of the $\mathrm{KBr}$ is desired, prepare a $4.5 \mathrm{mM}$ solution of reagent grade $\mathrm{AgNO}_{3}$ 181 (again after drying the reagent for 2 hours at $110^{\circ} \mathrm{C}$ followed by cooling to room temperature in a 182 desiccator). Using a calibrated pipet, transfer $40 \mathrm{ml}$ of the $\mathrm{AgNO}_{3}$ solution to the 125 -ml titration 183 vessel, and titrate with the $\mathrm{KBr}$ solution as described above for the diluted digestate samples. To 184 calibrate the total Fe determinations, prepare a set of 6 standards [FAS, for example] ranging from $185 \quad 0-32 \mathrm{mg}$ Fe and carry them through the digestion, dilution, and determination stages for total Fe.

186 Quantities of reagents and samples are best determined by gravimetry, and require determination 187 of the densities of the AgF-HF, $\mathrm{NH}_{2} \mathrm{OH}-\mathrm{H}_{3} \mathrm{BO}_{3}$, and citrate-phen solutions at the laboratory 188 temperature. 


\subsection{Results and Discussion}

\subsection{Modified colorimetric method}

192 A number of modifications were made to the method of Amonette and Templeton (1998) in an attempt

However, even with these changes, and careful sparging of all reagents with $\mathrm{N}_{2}$ inside the anoxic chamber prior to use, analysis of the geochemical standards and FAS showed that significant oxidation of Fe(II) occurred (Fig. 2). Thermodynamically, this would be expected due to the formation of a suite of strong Fe(III)-fluoride complexes and the lack of Fe(II)-fluoride complexes of comparable strength to maintain the initial $\mathrm{Fe}(\mathrm{II}) / \mathrm{Fe}(\mathrm{III})$ ratio. A time study of the rate of $\mathrm{Fe}(\mathrm{II})$ oxidation showed that it occurred during the first 4 hours of digestion (see Supplemental Information). Thereafter, no further oxidation occurred, suggesting that a new equilibrium had been obtained. Despite the disappointing results obtained for Fe(II), values for total Fe were in excellent agreement with the reference values (Fig. 2). 


\subsection{Hybrid oxidi-colorimetric method}

213 Having established a way to digest the spinels and measure their total Fe content we turned our 214 attention to finding a way to assay the Fe(II) content reliably. Clearly, the only option was to measure the Fe(II) by oxidimetry, but the challenge was to find an oxidant that was stable in neat $48 \% \mathrm{HF}$ at nearboiling temperatures for extended periods of time. Methods involving vanadate (e.g., Wilson, 1955; Amonette and Scott, 1990) could not be used due to the instability of the vanadate in the absence of $\mathrm{H}_{2} \mathrm{SO}_{4}$. Similar issues were expected with the other oxyanion-based oxidants, presumably due to the different complexation of the reduced form of the reagent (e.g., $\mathrm{VO}^{2+}, \mathrm{Cr}^{3+}$ ) by fluoride ions, which yielded a situation similar to that encountered for Fe(II) and Fe(III) in HF.

The $\operatorname{Ag}(I) / A g(m)$ couple, however, avoids this differential complexation issue. $A g(I)$ is readily soluble in $\mathrm{HF}$ and forms only a very weak complex with fluoride ( $\log \mathrm{K}=-0.32$, Smith and Martell, 1989), whereas $\mathrm{Ag}(\mathrm{m})$ is insoluble in $\mathrm{HF}$, and by virtue of being a solid does not form any fluoride complexes. Further, the formal reduction potential of the $\mathrm{Ag}(\mathrm{I}) / \mathrm{Ag}(\mathrm{m})$ couple $(+0.79 \mathrm{~V})$ is the same in concentrated $\mathrm{HF}$ as it is in water whereas that of the $\mathrm{Fe}(\mathrm{III}) / \mathrm{Fe}(\mathrm{II})$ couple is more than $0.4 \mathrm{~V}$ lower in concentrated $\mathrm{HF}$ making Fe(II) susceptible to oxidation by $\mathrm{Ag}(\mathrm{I})$ under those conditions. These features had been appreciated and a method published for analysis of $\mathrm{Fe}(\mathrm{II})$ in silicate minerals by $\mathrm{Ag}(\mathrm{I})$ by Ungethüm (1965). To ensure the suitability of the $\mathrm{Ag}(\mathrm{I})$ method in combination with the colorimetric method for measurement of total Fe, we had to adjust volumes analyzed and select the counter ion to eliminate any potential interferences with the phen complexation approach. Fortunately, the amount of sample needed for total Fe colorimetric analysis was very small, less than $1 \%$ of the total Fe present, and that left the rest of the digestate available for the titrimetric analysis of Fe(II).

\section{During the course of the testing of the hybrid oxidi-colorimetric method, several improvements were} made to Ungethüm's original approach. We conducted all work with $\mathrm{Ag}(\mathrm{I})$ solutions in the dark, or 
under reduced lighting, to avoid the potential for photoreduction (and a resultant high Fe(II) titer). We substituted $\mathrm{AgF}$ for the $\mathrm{AgClO}_{4}$ originally called for, to eliminate the possibility of any oxidation of $\mathrm{Fe}(\mathrm{II})$ by the anion. After an initial dilution with $\mathrm{H}_{2} \mathrm{O}$, which altered the formal reduction potential of the $\mathrm{Fe}(\mathrm{III}) / \mathrm{Fe}(\mathrm{II})$ couple such that it could oxidize $\mathrm{Ag}(\mathrm{m})$, we took a subsample for total Fe analysis and then immediately titrated the rest of the digest thus minimizing any loss of Fe(II) titer. And, after several failed attempts, we eliminated titration of standard samples containing FAS because the sulfate in the

\subsection{Reference standards}

245 When applied to analysis of the standard reference materials in two separate 6-replicate runs, the new 246 hybrid oxidi-colorimetric method yielded precise results in excellent agreement with published values 247 for all but one sample (Table 2, Fig. 3). Analysis of the Icelandic basalt standard, BIR-1, however, yielded 248 higher Fe(II) values and lower total Fe values than the corresponding reference values (Table 2, Fig. 4). 249 This sample was unique among the reference materials in that it contained significant quantities of $\mathrm{Mg}$ 250 (about 70\% more $\mathrm{Mg}$ than Fe on a molar basis). Given the well-known limited solubilities of $\mathrm{MgF}_{2}$ and $251 \mathrm{FeF}_{3}(\log \mathrm{Ksp}=-8.18$, Smith and Martell, 1989, and -6.95, respectively) and the generally observed 252 problems with dissolution of high-Mg materials in HF solutions (Amonette and Scott, 1991; Dowall et al., 253 2003), one can explain the low total Fe results as due to some form of co-precipitation of Fe(III) with $254 \mathrm{MgF}_{2}$ to form $(\mathrm{Mg}, \mathrm{Fe})$ fluoride solid solutions. Evidently, the boric acid added to the aliquot taken for 255 total Fe was insufficient to completely dissolve these precipitates.

256 As for the high values for Fe(II) obtained with BIR-1, we think it likely that the values we measured are 257 real, and that most of the previous analyses have not measured this Fe(II) due to issues associated with 
the formation of the (MgFe)-fluoride precipitates. In those instances, the precipitates likely contained

$\mathrm{Fe}(\mathrm{II})$ as well as $\mathrm{Mg}$ and $\mathrm{Fe}(\mathrm{III})$. In the present instance, the ability of $\mathrm{Ag}(\mathrm{I})$ to react with $\mathrm{Fe}(\mathrm{II})$ as soon as

260 it is released from the oxide matrix eliminates this concern.

261 Due to the significant Cu content of the magnetite ore reference standards, Fe(II) values obtained for

262 OREAS-700 and OREAS-701 were adjusted downward by the reported Cu concentrations for these two

263 standards. Monovalent $\mathrm{Cu}$ is oxidized by $\mathrm{Ag}(\mathrm{I})$ in the same way as $\mathrm{Fe}(\mathrm{II})$.

264 Table 2. Results of analysis of reference standards using the new hybrid oxidi-colorimetric method. All 265 values are weight percent.

\begin{tabular}{|l|c|c|c|c|c|c|c|}
\hline \multirow{2}{*}{ Sample } & \multirow{2}{*}{ Run } & \multicolumn{5}{|c|}{ Measured Values } & \multicolumn{2}{c|}{ Reference Values $^{\text {a }}$} \\
\cline { 3 - 8 } & \multirow{2}{*}{} & \multicolumn{2}{|c|}{ Fe(II) } & \multicolumn{2}{c|}{ Fe Total } & Fe(II) & Fe Total \\
\cline { 3 - 8 } & $1^{\mathrm{c}}$ & $1.22(0.25)$ & $5^{\mathrm{d}}$ & $1.78(0.28)$ & $5^{\mathrm{e}}$ & $1.13(0.12)$ & $1.86(0.14)$ \\
\hline G-2 & 1 & $7.30(0.48)$ & $5^{\mathrm{d}}$ & $6.82(0.33)$ & $5^{f}$ & $6.51(0.20)$ & $7.87(0.33)$ \\
\hline BIR-1 & 1 & $9.41(0.33)$ & 6 & $16.28(0.22)$ & $5^{f}$ & $9.38(0.62)$ & $16.06(0.35)$ \\
\hline OREAS 700 & $2^{\mathrm{g}}$ & $1.07(0.16)$ & 6 & $1.87(0.52)$ & 6 & $1.13(0.12)$ & $1.86(0.14)$ \\
\hline OREAS 701 & 1 & $13.47(0.25)$ & $5^{\mathrm{d}}$ & $24.22(0.31)$ & $5^{f}$ & $13.49(0.99)$ & $23.98(1.09)$ \\
\hline G-2 & 2 & $6.86(0.26)$ & $5^{\mathrm{d}}$ & $7.02(0.07)$ & $5^{f}$ & $6.51(0.20)$ & $7.87(0.33)$ \\
\hline BIR-1 & 2 & $9.44(0.21)$ & 6 & $16.21(0.31)$ & 6 & $9.38(0.62)$ & $16.06(0.35)$ \\
\hline OREAS 700 & 2 & $13.54(0.05)$ & $5^{f}$ & $24.06(1.80)$ & $5^{f}$ & $13.49(0.99)$ & $23.98(1.09)$ \\
\hline OREAS 701 & 2 & & & & \\
\hline
\end{tabular}

266 a Gladney et al. $(1988,1992)$, and datapacks provided by OREAS

$267{ }^{\mathrm{b}} \mathrm{Cl}$ is $95 \%$ confidence interval

268 'SRM-8, 28 March 2015

$269{ }^{d}$ rep lost due to titration overshoot

270 erep not analyzed

271 outlier data point removed using $Q$ test at $p=0.95$ (Rorabacher, 1991)

272 SSRM-9, 25 April 2015 


\subsection{Spinel samples}

275 To demonstrate applicability of the method to the analysis of spinel samples, a set of five samples of $276 \mathrm{Fe}(\mathrm{Ni})$ spinel crystals (Figure 5) isolated from a simulated glass being considered for storage of nuclear

277 waste was analyzed in triplicate. Also analyzed were four reagent magnetite $\left(\mathrm{Fe}_{3} \mathrm{O}_{4}\right)$ specimens. Two of 278 these (ALP, AAP) were high-metal-purity nominally stoichiometric magnetite, a third (ALN) was a nano279 sized magnetite, and the fourth (OQ) was synthesized in-house and had seen minimal processing or 280 handling under atmospheric conditions.

281 The results of these analyses showed levels of Fe(II) at the detection limit for the spinel crystals, 282 consistent with the earlier Mössbauer results, and values of total Fe slightly, but consistently, higher 283 than those obtained by separate elemental analysis (Table 3). The magnetites yielded a wide range of $284 \mathrm{Fe}(\mathrm{II})$ values, with the in-house sample (OQ) being closest to stoichiometric magnetite (about $92 \%$ 285 magnetite), and the nano-sized magnetite (ALN) having only about $20 \%$ stoichiometric magnetite. The 286 two high-purity samples showed more oxidation than the in-house sample, but came from containers 287 that had been opened a few months earlier and had not been stored under $\mathrm{N}_{2}$. Total Fe results were in 288 good agreement with values reported by the manufacturers (Table 3).

\subsection{Accuracy and Precision}

290 The accuracy of the hybrid method was formally assessed by calculation of four parameters that 291 compare the measured and reference data. Thus, the assessment of accuracy depends not only on the 292 quality of the measurements made by the hybrid method, but also on the quality of the measurements 293 contributing to the reference value. 
The first and simplest parameter, $d$, is the size of the difference between the measured and reference

${ }^{\mathrm{a}} \mathrm{Cl}$ is $95 \%$ confidence interval

${ }^{b}$ Spinel crystal isolated from a simulated HLW glass having an initial Ni/Fe ratio of 1.5/17.5 and treated at $900^{\circ} \mathrm{C}$ for 2 to 10 days (Matyáš et al., 2014)

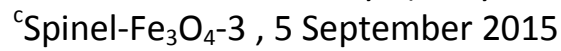

${ }^{d}$ Determined by ICP-AES analysis after lithium metaborate/tetraborate fusion, $95 \%$ confidence interval estimated from one set of duplicates and applied to all samples (Matyáš et al., 2014)

erep lost due to titration overshoot

fnominal value calculated assuming ideal purity and stoichiometry

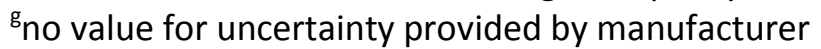

data for a given sample (i.e., $d=$ measured value minus reference value). By its sign, this parameter gives an idea of whether the method is giving results that are higher or lower than the reference values.

The second parameter, $|d|$, is the absolute value of $d$, which gives an idea of the overall size of the difference without assessing whether it is higher or lower than the reference value. This parameter is most useful for calculating the mean difference obtained for a particular method or set of samples. The 
third parameter, $\mathrm{RD}$, is the relative difference (i.e., $\mathrm{RD}=100^{*}|d| / \mathrm{RV}$, where $\mathrm{RV}$ is the reference value 314 for a given sample). This parameter normalized the size of the analytical difference to the amount of 315 analyte present in the sample. The fourth, and most complex, parameter is $\left|t^{\prime}\right|$, which is similar to the

For Fe(II) measurements, the method accuracy was excellent for three of the four SRMs with mean differences of $0.02 \mathrm{wt} \%$, an RD of $0.4 \%$ and a $\left|t^{\prime}\right|$ value less than 0.5 . The exception was BIR-1, for which large positive $d$ values were obtained along with a $\left|t^{\prime}\right|$ value that was significant at the $95 \%$ probability level. As discussed in Section 3.3, it is likely that these differences reflect an artifact common to most methods employing HF digestion and thus the reference value for Fe(II) in BIR-1 is likely too low. As a result, in addition to calculating parameter means for all four SRM samples, we calculated a separate set of means for the other three SRMS to more truly reflect the accuracy of the hybrid method. 
For total Fe measurements, we calculated accuracy parameters for the five spinel samples as well as for the SRMs since we had an independent set of total-Fe data for the spinels that we could use as a reference. As for Fe(II), the results showed good accuracy for three of the SRMs and considerably poorer accuracy for BIR-1. In this instance, however, the formation of MgFe(III) fluoride complexes may have been responsible for the lower total Fe results with BIR-1 obtained by the hybrid method. Accuracy for the spinel samples was roughly comparable to that for the four SRMs with RD values of 3.9 $\%$ and $\left|t^{\prime}\right|$ values averaging 6.4-6.8, well above the level of significance at $95 \%$ probability. The reference values for the spinels were not "certified" and represented, at most, the results of duplicate analyses, but the generally positive trends in the $d$ values suggested that the hybrid method was more successful in achieving complete dissolution and recovery of Fe from these samples than the reference method. Because of the uncertainty in the spinel reference data and the problem with the BIR-1 analysis, our overall interpretation of the accuracy for total Fe focuses on the remaining three SRM samples. For G-2, excellent accuracy was obtained. For the two OREAS samples, generally higher totalFe values were measured (by 0.16-0.19 wt\%) than for the reference method (borate fusion with XRF analysis), and for OREAS 700 the difference was significant $(P=0.95)$ by the $\left|t^{\prime}\right|$ test. The OREAS datapacks also give values for total Fe obtained by two acid-dissolution methods that were substantially lower than the fusion/XRF values. It is unclear, therefore, whether the true values for total Fe in these two SRMS are those obtained by the hybrid method or by the fusion/XRF method. Taken as a whole, RD values averaged $1.2 \%$ and the mean $\left|t^{\prime}\right|$ value was below the level of significance $(P=0.95)$ for the three SRM samples indicating that adequate accuracy was obtained for total Fe by the hybrid method. 
Table 4. Several measures of the accuracy of the hybrid oxidi-colorimetric method.

\begin{tabular}{|c|c|c|c|c|c|c|c|c|}
\hline \multirow[b]{3}{*}{ Sample } & \multicolumn{4}{|c|}{$\mathrm{Fe}(\mathrm{II})$} & \multicolumn{4}{|c|}{ Total Fe } \\
\hline & $d^{a}$ & $|d|^{b}$ & $\mathrm{RD}^{\mathrm{c}}$ & $\left|t^{\prime}\right|^{d}$ & d & $|d|$ & $\mathrm{RD}$ & $\left|t^{\prime}\right|$ \\
\hline & \multicolumn{2}{|c|}{----- wt\% ----- } & $\%$ & & \multicolumn{2}{|c|}{------- wt\% ------- } & $\%$ & \\
\hline Spinel $13^{a}$ & $-{ }^{e}$ & -- & -- & -- & 2.28 & 2.28 & 5.2 & 21.405 \\
\hline Spinel 14 & -- & -- & -- & -- & 0.21 & 0.21 & 0.5 & 0.631 \\
\hline Spinel 15 & -- & -- & -- & -- & 1.58 & 1.58 & 3.6 & 2.217 \\
\hline Spinel 16 & -- & -- & -- & -- & 2.93 & 2.93 & 6.8 & 9.705 \\
\hline Spinel 17 & -- & -- & -- & -- & 1.27 & 1.27 & 2.9 & 1.526 \\
\hline G-2 & 0.01 & 0.01 & 0.6 & 0.195 & -0.03 & 0.03 & 1.7 & 0.620 \\
\hline BIR-1 & 0.57 & 0.57 & 8.7 & 6.326 & -0.95 & 0.95 & 12.1 & 19.161 \\
\hline OREAS 700 & 0.04 & 0.04 & 0.5 & 0.872 & 0.19 & 0.19 & 1.2 & 4.829 \\
\hline OREAS 701 & 0.02 & 0.02 & 0.2 & 0.371 & 0.16 & 0.16 & 0.7 & 1.161 \\
\hline Means & 0.16 & 0.16 & 2.5 & 1.941 & 0.85 & 1.07 & 3.9 & 6.806 \\
\hline SRM means & 0.16 & 0.16 & 2.5 & 1.941 & -0.16 & 0.33 & 3.9 & 6.443 \\
\hline w/o BIR-1 & 0.02 & 0.02 & 0.4 & 0.479 & 0.11 & 0.13 & 1.2 & 2.203 \\
\hline
\end{tabular}

a difference between measured and reference values (i.e., measured value minus reference value)

babsolute value of difference between measured and reference values

'relative difference (i.e., $(|d| * 100) / R$, where $R$ is the reference value)

${ }^{d}$ calculated $t$ statistic for unpaired samples from populations having unequal variances (see p. 81 in Steel and Torrey, 1960); bold, shaded entries indicate values of $t^{\prime}$ that are significant at $\mathrm{P}=0.95$ (i.e., the null hypothesis, $\mathrm{H}_{0}$, that measured and reference populations have equal means is likely to be false) enot applicable (no reference data exist for these samples).

Formal assessment of precision of the hybrid method involved calculation of three parameters, the standard deviation (SD), the relative standard deviation (RSD), and the $95 \%$ confidence interval. As these calculations did not require reference data, all of the samples analyzed were included in the assessment. The results (Table 5) showed a mean SD of 0.23 wt\%, a mean RSD of $6.3 \%$, and a $95 \%$ confidence interval of $1.38 \%$ for Fe(II). Corresponding values for total Fe were 0.48 wt $\%, 1.8 \%$, and 2.72 371 detection limit. For the SRM samples, SD values ranged from 0.1 to $0.4 \mathrm{wt} \%$, RSD values from 0.5 to 
9.3\%, and $95 \%$ confidence intervals from 0.2 to $0.9 w t \%$ for both Fe(II) and total Fe. The results for BIR-1 were not substantially different from the other three SRMs. Although there were no sample-specific

SD is the standard deviation

${ }^{\mathrm{b}} \mathrm{RSD}$ is the relative standard deviation, i.e., (100*SD/mean)

${ }^{\mathrm{C}} \mathrm{Cl}$ is the $95 \%$ confidence interval

dSRMS are G-2, BIR-1, OREAS 700 and OREAS 701

trends in SD values for Fe(II), for total Fe the SD and Cl values obtained for the spinel and magnetite

382 levels measured. In general, precision of the hybrid method was adequate for both Fe(II) and total Fe. 


\subsection{Comparison with Existing Methods}

384 As discussed by Abbey (1981) assessing the accuracy of different methods, even when analyzing the

same SRM, represents a formidable challenge. And trying to compare different methods analyzing different SRMs may well be impossible. Nevertheless, we think some insight can be derived from applying a consistent statistical approach to the results obtained by a range of methods analyzing wellcharacterized SRMs, so long as we recognize that 1) "accuracy" is a continuously evolving relative term, and 2) comparing methods developed for different purposes and types of samples in general terms may overlook the special attributes that these methods have for their original purpose.

To compare the performance of the hybrid method with that of comparable existing methods for silicates and refractory materials, assessments of accuracy and precision identical to those described in Section 3.5 were completed for 13 published methods, five of which determined both Fe(II) and total Fe. Of these methods, three (Ayranci, 1992; Donaldson, 1969; Meyrowitz, 1970) were specifically aimed at refractory samples and involved decomposition by borate fusion followed by Fe(II) determination using oxidimetry or colorimetry. Only that of Ayranci (1992), however, also determined total Fe. The remaining 10 methods were designed for analysis of non-refractory minerals and rocks, and four of these measured both Fe(II) and total Fe. A total suite of 47 SRMS were analyzed by these methods, and the reference values for these (means, standard deviations, and numbers of analyses) were obtained primarily from Govindaraju (1994) and references cited therein. A full listing of the SRMs, the individual results obtained for each method, and the literature used for reference values is given in the Supplemental Information. In order to compare the methods, however, only the means of the results obtained for each of the four accuracy parameters $\left(d,|d|, R D\right.$, and $\left.\left|t^{\prime}\right|\right)$ and the three precision parameters (SD, RSD, and $\mathrm{Cl}$ ) are provided here. In addition to mean values for each method/parameter combination, grand means for all the existing methods were also calculated along with a "percentile 
score" that placed the mean obtained for the hybrid method in the range of those obtained by all the methods. The worst mean at one end of the range of values was assigned a percentile score of 0 and the best mean at the other end of the range a score of 100 . The mean for the hybrid method was then compared to these two means, and its position in the range of values normalized on a scale of 0 to 100 . Thus, a percentile score of 90 indicates the mean for the hybrid method was $90 \%$ along the range between the worst and the best means.

412 In terms of accuracy (Table 6), the hybrid method performed extraordinarily well for Fe(II), with 413 percentile scores near 90 for $\left|t^{\prime}\right|$ and RD and, when the BIR-1 data was excluded, scores of $99-100$ for all 414 four parameters. Two other methods were comparable to the hybrid method in terms of Fe(II) 415 accuracy. The fusion/colorimetric method of Ayranci (1992), and the rapid $\mathrm{HF}-\mathrm{H}_{2} \mathrm{SO}_{4}$ decomposition 416 method of Begheijn (1979) with colorimetric determination of Fe(II) yielded almost identical accuracy 417 ratings. Of the two, however, only Ayranci's method would be applicable to analysis of refractory spinel 418 samples. Very good accuracy for Fe(II) was obtained by the method of Husler et al. (2011), which also 419 employed a rapid acid-decomposition approach followed by colorimetric analysis. The hybrid method 420 clearly represents an improvement in accuracy over the original method employing $\mathrm{Ag}(\mathrm{I})$ published by 421 Ungethüm (1965), although lack of replicate data did not allow estimation of the $\left|t^{\prime}\right|$ parameter for 422 Ungethüm's method.

423 For total Fe accuracy, the hybrid method performed very well with RD and $\left|t^{\prime}\right|$ percentile scores of 99 424 and 85, respectively, when the BIR-1 data were not considered. The methods of Husler et al. (2011) and 425 Ayranci (1992) yielded comparable results to the hybrid method. The measured and reference total-Fe 426 data presented by Husler et al (2011), however, are incorrect due to a unit-conversion error. Correct 427 values were kindly supplied by E. A. D. Ferriss (personal communication, 10 December 2015). 
428 Table 6. Comparison of accuracy of the hybrid oxidi-colorimetric method with that of other selected

429 wet-chemical methods when applied to standard reference materials (SRMs). Values are overall means

430 for all the SRM samples analyzed by a particular method.

\begin{tabular}{|c|c|c|c|c|c|c|c|c|c|c|}
\hline & & & & & & & & Tot & & \\
\hline & & & $d^{c}$ & $|d|^{d}$ & $\mathrm{RD}^{\mathrm{e}}$ & $\left|t^{\prime}\right|^{f}$ & $\mathrm{~d}$ & $|d|$ & $\mathrm{RD}$ & $\left|t^{\prime}\right|$ \\
\hline Method & $\mathrm{N}^{\mathrm{a}}$ & $n^{b}$ & $----n$ & $\%$----- & $\%$ & & $----n$ & 6 ----- & $\%$ & \\
\hline $\begin{array}{c}\text { Hybrid } \\
\text { (this method) }\end{array}$ & 4 & 43 & 0.16 & 0.16 & 2.5 & 1.94 & -0.16 & 0.33 & 3.9 & 6.44 \\
\hline $\begin{array}{c}\text { Hybrid } \\
\text { (w/o BIR-1 data) }\end{array}$ & 3 & 33 & 0.02 & 0.02 & 0.4 & 0.48 & 0.11 & 0.13 & 1.2 & 2.20 \\
\hline $\begin{array}{c}\text { Amonette \& Scott } \\
\text { (1991) }\end{array}$ & 5 & 47 & 0.07 & 0.09 & 2.8 & 3.83 & $-\mathrm{g}^{\mathrm{g}}$ & -- & -- & -- \\
\hline $\begin{array}{c}\text { Amonette \& Templeton } \\
\text { (1998) }\end{array}$ & 5 & 29 & 0.07 & 0.17 & 2.4 & 4.04 & -0.03 & 0.12 & 2.7 & 4.94 \\
\hline $\begin{array}{l}\text { Andrade et al. } \\
\text { (2002) }\end{array}$ & 9 & 49 & 0.01 & 0.12 & 18.3 & 1.77 & -- & -- & -- & -- \\
\hline $\begin{array}{c}\text { Ayranci } \\
\text { (1992) }\end{array}$ & 7 & 12 & -0.02 & 0.03 & 3.2 & $--^{h}$ & 0.05 & 0.06 & 3.6 & $1.46^{h}$ \\
\hline $\begin{array}{c}\text { Banerjee } \\
(1974)\end{array}$ & 11 & 44 & 0.03 & 0.13 & 1.9 & 2.39 & -- & -- & -- & -- \\
\hline $\begin{array}{c}\text { Begheijn } \\
\text { (1979) }\end{array}$ & 5 & 30 & 0.02 & 0.02 & 0.6 & 0.51 & -0.12 & 0.19 & 3.4 & 7.56 \\
\hline $\begin{array}{c}\text { Donaldson } \\
\text { (1969) acid dissolution }\end{array}$ & 8 & 30 & 0.09 & 0.11 & 3.6 & 4.29 & - & -- & -- & -- \\
\hline $\begin{array}{l}\text { Donaldson } \\
\text { (1969) fusion }\end{array}$ & 8 & 30 & 0.35 & 0.37 & 18.2 & 15.7 & -- & -- & -- & -- \\
\hline $\begin{array}{l}\text { Husler et al. } \\
\text { (2011) }\end{array}$ & 8 & 21 & -0.03 & 0.09 & 1.3 & 1.19 & 0.02 & 0.14 & 1.1 & 1.28 \\
\hline $\begin{array}{c}\text { Kiss } \\
(1987)\end{array}$ & 2 & 8 & 0.06 & 0.24 & 4.1 & 2.67 & -- & -- & -- & -- \\
\hline $\begin{array}{l}\text { Meyrowitz } \\
(1970)\end{array}$ & 4 & 8 & 0.17 & 0.30 & 5.8 & 8.22 & -- & - & -- & -- \\
\hline $\begin{array}{c}\text { Tarafder \& Thakur } \\
\text { (2013) }\end{array}$ & 13 & 65 & -0.19 & 0.28 & 13.8 & 2.20 & 0.08 & 0.18 & 7.5 & 2.30 \\
\hline $\begin{array}{l}\text { Ungethüm } \\
\text { (1965) }\end{array}$ & 5 & 5 & 0.06 & 0.06 & 6.5 & $--^{i}$ & -- & - & -- & -- \\
\hline $\begin{array}{c}\text { Grand means (except } \\
\text { method) }\end{array}$ & Hyk & & 0.05 & 0.16 & 6.3 & 4.25 & 0.00 & 0.14 & 3.6 & 4.02 \\
\hline Hybrid percentile & core & & 60 & 60 & 89 & 91 & 0 & 0 & 56 & 18 \\
\hline Hybrid percentile score & N/O B & & 99 & 99 & 100 & 100 & 49 & 49 & 99 & 85 \\
\hline
\end{tabular}

431

${ }^{a}$ Number of SRMs analyzed 
${ }^{\mathrm{b}}$ Total number of samples analyzed

'difference between measured and reference values (i.e., measured value minus reference value)

dabsolute value of difference between measured and reference values

erelative difference (i.e., $(|d| * 100) / R$, where $R$ is the reference value)

${ }^{f}$ calculated $t$ statistic for unpaired samples from populations having unequal variances (see p. 81 in Steel and Torrey, 1960); bold, shaded entries indicate values of $t^{\prime}$ that are significant at $P=0.95$ (i.e., the null hypothesis, $\mathrm{H}_{0}$, that measured and reference populations have equal means is likely to be false) ${ }^{\mathrm{g}}$ no total Fe data measured

insufficient reference-value replication data reported to calculate $\left|t^{\prime}\right|$ insufficient measured-value replication data reported to calculate $\left|t^{\prime}\right|$

In terms of precision (Table 7), the performance of the hybrid method was mixed. When compared on the basis of SD and RSD values, it was not as strong a performer as most of the other methods with SD values as much as twice the grand mean and RSD values 1.6 times higher. As a result, the percentile scores for SD were 35 for Fe(II) and only 11 for total Fe. Percentile scores for RSD were near 45 for both Fe(II) and total Fe. However, when compared on the basis of $95 \%$ confidence intervals, the method performed well, with a lower $\mathrm{Cl}$ than the grand mean, and percentile scores near 80 for both Fe(II) and total Fe. The methods of Amonette and Scott (1991), Amonette and Templeton (1998), and Donaldson (1969, acid dissolution) yielded better precision. The mixed performance of the hybrid method in terms of precision is likely due to the long digestion period and more extensive sample handling employed.

One method not included in our analysis was the iodine monochloride method of Hey $(1941 ; 1982)$, which when combined with fusion decomposition using Ayranci's approach (1992) would seem to be an excellent method. Unfortunately, neither of Hey's papers provide the SRM data needed for a statistical analysis and so we could not include the method in our comparison. We were able to include an aciddissolution method using iodine monochloride by Banerjee (1974) in which the author notes the chief difficulty was in obtaining complete decomposition of the samples. 


\begin{tabular}{|c|c|c|c|c|c|c|c|c|}
\hline \multirow[b]{3}{*}{ Method } & \multirow[b]{3}{*}{$\mathrm{N}^{\mathrm{a}}$} & \multirow[b]{3}{*}{$n^{b}$} & \multicolumn{3}{|c|}{$\mathrm{Fe}(\mathrm{II})$} & \multicolumn{3}{|c|}{ Total Fe } \\
\hline & & & $S D^{c}$ & $\mathrm{RSD}^{\mathrm{d}}$ & $\mathrm{Cl}^{\mathrm{e}}$ & SD & RSD & $\mathrm{Cl}$ \\
\hline & & & wt\% & $\%$ & wt\% & wt\% & $\%$ & wt\% \\
\hline $\begin{array}{c}\text { Hybrid } \\
\text { (this method) }\end{array}$ & 4 & 43 & 0.14 & 3.7 & 0.31 & 0.20 & 3.3 & 0.45 \\
\hline $\begin{array}{c}\text { Amonette \& Scott } \\
\text { (1991) }\end{array}$ & 5 & 47 & 0.02 & 0.4 & 0.05 & $--^{f}$ & -- & -- \\
\hline $\begin{array}{c}\text { Amonette \& Templeton } \\
\text { (1998) }\end{array}$ & 5 & 29 & 0.03 & 0.6 & 0.09 & 0.04 & 0.6 & 0.11 \\
\hline $\begin{array}{l}\text { Andrade et al. } \\
(2002)\end{array}$ & 9 & 49 & 0.11 & 6.5 & 0.30 & -- & -- & -- \\
\hline $\begin{array}{c}\text { Ayranci } \\
(1992)\end{array}$ & 3 & 8 & 0.04 & 1.4 & 0.33 & 0.04 & 1.9 & 0.24 \\
\hline $\begin{array}{c}\text { Banerjee } \\
(1974)\end{array}$ & 11 & 44 & 0.04 & 2.2 & 0.14 & -- & -- & -- \\
\hline $\begin{array}{c}\text { Begheijn } \\
(1979)\end{array}$ & 5 & 30 & 0.07 & 3.0 & 0.18 & 0.07 & 1.9 & 0.19 \\
\hline $\begin{array}{c}\text { Donaldson } \\
\text { (1969) acid dissolution }\end{array}$ & 8 & 30 & 0.02 & 1.0 & 0.08 & -- & -- & -- \\
\hline $\begin{array}{l}\text { Donaldson } \\
\text { (1969) fusion }\end{array}$ & 8 & 30 & 0.06 & 1.6 & 0.19 & -- & -- & -- \\
\hline $\begin{array}{l}\text { Husler et al. } \\
\text { (2011) }\end{array}$ & 8 & 21 & 0.15 & 1.8 & 1.42 & 0.21 & 1.6 & 1.69 \\
\hline $\begin{array}{c}\text { Kiss } \\
(1987)\end{array}$ & 2 & 8 & 020 & 3.4 & 0.64 & -- & -- & -- \\
\hline $\begin{array}{c}\text { Meyrowitz } \\
(1970)\end{array}$ & 4 & 8 & 0.06 & 1.1 & 0.82 & -- & -- & -- \\
\hline $\begin{array}{c}\text { Tarafder \& Thakur } \\
\text { (2013) }\end{array}$ & 13 & 65 & 0.12 & 5.0 & 0.34 & 0.22 & 5.5 & 0.61 \\
\hline \multicolumn{3}{|c|}{ Grand means (except for Hybrid method) } & 0.08 & 2.3 & 0.38 & 0.12 & 2.3 & 0.57 \\
\hline \multicolumn{3}{|c|}{ Hybrid percentile (continuous) } & 35 & 46 & 81 & 11 & 44 & 78 \\
\hline
\end{tabular}

${ }^{\mathrm{a}}$ Number of SRMs analyzed

${ }^{\mathrm{b}}$ Total number of samples analyzed

${ }^{\mathrm{c}} \mathrm{SD}$ is the standard deviation

${ }^{d} \mathrm{RSD}$ is the relative standard deviation, i.e., (100*SD/mean)

${ }^{\mathrm{e}} \mathrm{Cl}$ is the $95 \%$ confidence interval

fno total Fe data measured 
Overall, the main strengths of the hybrid method relative to the existing methods are the high accuracy

for Fe(II) and total Fe, and the ability to analyze refractory spinels. This is achieved with somewhat poorer, though still adequate, precision. Only one existing method, that of Ayranci (1992), can

determine $\mathrm{Fe}(\mathrm{II})$ and total Fe in refractory samples with apparently comparable accuracy, and that method requires a special apparatus for fusion decomposition under an inert atmosphere and the use of $\mathrm{Pt} / \mathrm{Au}$ alloy crucibles. However, even with the use of Pt/Au crucibles, the ability of fusion decomposition to obtain accurate values for Fe(II) has been questioned by Donaldson (1969) on the basis of hightemperature equilibrium considerations. The hybrid method also has the advantage of a much smallervolume waste stream than many of the existing methods, such as those of Ayranci (1992), Amonette and Scott (1991) and Amonette and Templeton (1998), and the ability to completely recover the Ag precipitated as $\mathrm{Ag}(\mathrm{m})$ or $\mathrm{AgBr}$. The chief disadvantages of the hybrid method are the long digestion period required, the maintenance of low lighting conditions during the digestion and Fe(II) titration steps, and the need to perform both potentiometric and colorimetric analyses. And, as noted for BIR-1, the hybrid method does not obtain accurate total Fe values for samples with high Mg contents.

\subsection{Conclusions}

The hybrid oxidi-colorimetric method resolves most of the problems associated with Fe(II) and total Fe analysis of Fe-bearing spinels. Although the time for digestion is quite lengthy, results obtained for a series of geochemical reference materials, including two magnetite ores, as well as for reagent magnetites, are consistent with expectations. Anomalous values for a Mg-rich basalt (BIR-1), however, yielded higher Fe(II) and lower total Fe values than expected. These results can be attributed to the formation of MgFe(III)-fluoride precipitates that were not completely re-dissolved by boric acid after digestion, and by the likely presence of Fe(II) in similar precipitates analyzed by other groups that was not counted in the Fe(II) titers they obtained. The presence of $\mathrm{Ag}(\mathrm{I})$ in the digestate ensures that all 
$\mathrm{Fe}(\mathrm{II})$ is reacted upon dissolution of the oxide matrix, and the "noble" stability of $\mathrm{Ag}(\mathrm{m})$ in concentrated HF maintains the Fe(II) titer for at least 48 hours at near-boiling temperatures. Provided that evaporation of the digestate does not occur, it is likely that much longer digestions are possible, if needed, for highly recalcitrant samples. Because of its very high accuracy for Fe(II), we expect this method to be fully applicable to non-refractory samples as well, and thus of wide utility in the wetchemical determination of iron redox states.

\section{Acknowledgments}

498 This project has been supported by the U.S. Department of Energy's Waste Treatment and 499 Immobilization Plant Federal Project Office under the direction of Dr. Albert A. Kruger. Pacific

500 Northwest National Laboratory is operated by Battelle for the U.S. Department of Energy under 501 Contract DE-AC05-76RL01830. We thank Odeta Qafoku for preparing and providing samples of the in502 house-synthesized magnetite analyzed.

503 References

504 1. Abbey, S. 1981. Reliability in the analysis of rocks and minerals. Analytical Chemistry 53:528A534A.

2. Amonette, JE, FA Khan, H Gan, JW Stucki, and AD Scott. 1994. Quantitative oxidation-state analysis of soils. In (JE Amonette and LW Zelazny, eds.) Quantitative Methods in Soil Mineralogy. SSSA Miscellaneous Publication, Soil Science Society of America, Madison, WI, p. 83-113.

3. Amonette JE and AD Scott. 1991. Determination of ferrous iron in non-refractory silicate minerals-1. An improved semi-micro oxidimetric method. Chemical Geology 92:329-338. 
4. Amonette JE and JC Templeton. 1998. Improvements to the quantitative assay of nonrefractory minerals for Fe(II) and total Fe using 1,10-phenanthroline. Clays and Clay Minerals 46:51-62.

5. Andrade S, R Hypolito, HHGJ Ulbrich, and ML Silva. 2002. Iron(II) oxide determination in rocks and minerals. Chemical Geology 182:85-89

6. Ayranci B. 1992. Analysis of the oxidation states of iron in silicate rocks and refractory minerals by fusion disintegration. Kontakte (Darmstad) 1992:16-20.

7. Banerjee S. 1974. Direct determination of ferrous iron in silicate rocks and minerals by iodine monochloride. Analytical Chemistry 46:782-787.

8. Begheijn LTh. 1979. Determination of iron(II) in rock, soil, and clay. Analyst 104:1055-1061.

9. Donaldson EM. 1969. Study of Grove's method for determination of ferrous iron in refractory silicates. Analytical Chemistry 41:501-505.

10. Dowall, DP, GM Nowell, and DG Pearson. 2003. Chemical preconcentration procedures for high-precision analysis of $\mathrm{Hf}-\mathrm{Nd}$-Sr isotopes in geological materials by plasma ionisation multicollector mass spectrometry (PIMMS) techniques. In (Grenville Holland and Scott D. Tanner, eds.) Plasma source mass spectrometry: Applications and emerging technologies. Special Publication, Royal Society of Chemistry, Cambridge, UK, p. 321-337.

11. Gladney ES and I Roelandts. 1988. 1987 compilation of elemental concentration data for USGS BIR-1, DNC-1 and W-2. Geostandards Newsletter 12:63-118.

12. Gladney ES, EA Jones, EJ Nickell, and I Roelandts. 1992. 1988 compilation of elemental concentration data for USGS AGV-1, GSP-1, and G-2. Geostandards Newsletter 16:111-300.

13. Govindaraju K. 1994. 1994 compilation of working values and sample description for 383 geostandards. Geostandards Newsletter 18:1-156. 
14. Husler J, EDA Ferriss, KB Helean, CR Bryan, and PV Brady. 2011. Optimised ferrozine micromethod for the determination of ferrous and ferric iron in rocks and minerals. Geostandards and Geoanalytical Research 35:39-44.

15. Kiss E. 1987. Integrated scheme for micro-determination of iron oxidation states in silicates and refractory materials. Analytica Chimica Acta 193:51-60.

16. Komadel $\mathrm{P}$ and JW Stucki. 1988. The quantitative assay of minerals for $\mathrm{Fe}^{2+}$ and $\mathrm{Fe}^{3+}$ using $1,10-$ phenanthroline. III. A rapid photochemical method. Clays and Clay Minerals 36:379-381.

17. Matyáš, J, JD Vienna, A Kimura, M Schaible, and RM Tate. 2010. Development of crystaltolerant waste glasses, In Advances in Materials Science for Environmental and Nuclear Technology, Ceramic Transactions 222:41-51.

18. Matyáš, J, JD Vienna, and M Schaible. 2011. Determination of Stokes shape factor for single particles and agglomerates, In Advances in Materials Science for Environmental and Nuclear Technology II, Ceramic Transactions 227:195-203.

19. Matyáš, J, JE Amonette, RK Kukkadapu, DK Schreiber, and AA Kruger. 2014. The effects of glass doping, temperature, and time on the morphology, composition, and iron redox of spinel crystals. In Advances in Materials Science for Environmental and Energy Technologies III: Ceramic Transactions, 250:147-156.

20. Matyáš, J, GJ Sevigny, MJ Schweiger, and AA Kruger. 2015. Research-scale melter: An experimental platform for evaluating crystal accumulation in high-level waste glasses. In Advances in Materials Science for Environmental and Energy Technologies IV, Ceramic Transactions 253:49-59.

21. Meyrowitz R. 1970. New semimicroprocedure for determination of ferrous iron in refractory silicate minerals using a sodium metafluoborate decomposition. Analytical Chemistry 42:11101113. 
22. Rorabacher, DB. 1991. Statistical treatment for rejection of deviant values: critical values of Dixon's " $Q$ " parameter and related subrange ratios at the $95 \%$ confidence level. Analytical $560 \quad$ Chemistry 63:139-146.

23. Schafer, HNS. 1966. The determination of iron(II) oxide in silicate and refractory minerals - I. A review. Analyst 91:755-762.

24. Schwertmann, $U$, and RM Cornell. 2000. Iron oxides in the laboratory, $2^{\text {nd }}$ edition. Wiley-VCH, Berlin, Germany.

25. Steele, RGD and JH Torrie. 1960. Principles and procedures of statistics with special reference to the biological sciences. McGraw-Hill Book Company, Inc., New York.

26. Stucki, JW. 1981. The quantitative assay of minerals for $\mathrm{Fe}^{2+}$ and $\mathrm{Fe}^{3+}$ using 1,10phenanthroline. II. A photochemical method. Soil Science Society of America Journal 45:638641.

27. Tarafder PK and R Thakur. 2013. An optimised 1,10-phenanthroline method for the determination of ferrous and ferric oxides in silicate rocks, soils and minerals. Geostandards and Geoanalytical Research 37:155-168.

28. Ungethüm, H. 1965. Eine neue methode zur bestimmung von eisen(II) in gesteinen and mineralen, in besondere auch in bitumenhaltigen proben. Zeitschrift fur Angewandte Geologie 11:500-505.

29. Wilson AD. 1955. A new method for the determination of ferrous iron in rocks and minerals. Bulletin of the Geological Survey of Great Britain 1955(9):56-58. 


\section{Figure Captions}

580 Figure 1. Flow chart of hybrid oxidi-colorimetric method for Fe(II) and total Fe in refractory spinels.

581 Figure 2. Comparison of measured and reference values for analysis of four geochemical reference 582 materials and ferrous ammonium sulfate by the modified colorimetric method. Solid line indicates exact 583 agreement (1:1). Dashed line is regression of Fe(II) results [Fe(measured) $=0.884^{*}($ Fe(reference $)-$ $\left.5840.734, r^{2}=0.993\right]$. Error bars are one standard deviation.

585 Figure 3. Comparison of measured and reference values for analysis of four geochemical reference 586 materials and ferrous ammonium sulfate by the hybrid oxidi-colorimetric method. Solid line indicates 587 exact agreement (1:1). Error bars of one standard deviation are smaller than the symbols plotted.

588 Figure 4. Differences from the reference values for Fe(II) and total Fe obtained by the hybrid oxidi589 colorimetric method for each geochemical reference material and for FAS (total Fe only). Error bars are 590 one standard deviation.

591 Figure 5. Backscattered electron SEM image of crystals of Spinel 15. Crystals were isolated from

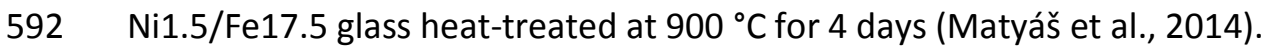


INITIAL PREPARATION

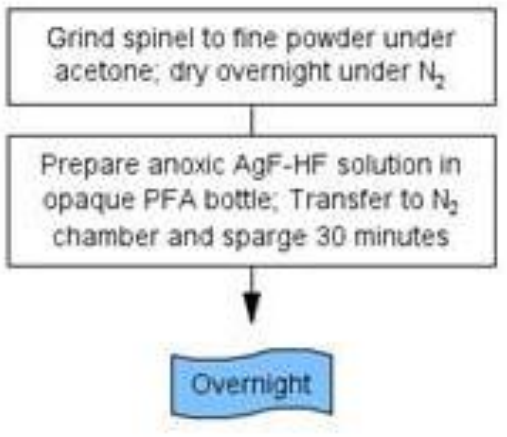

\section{DIGESTION}

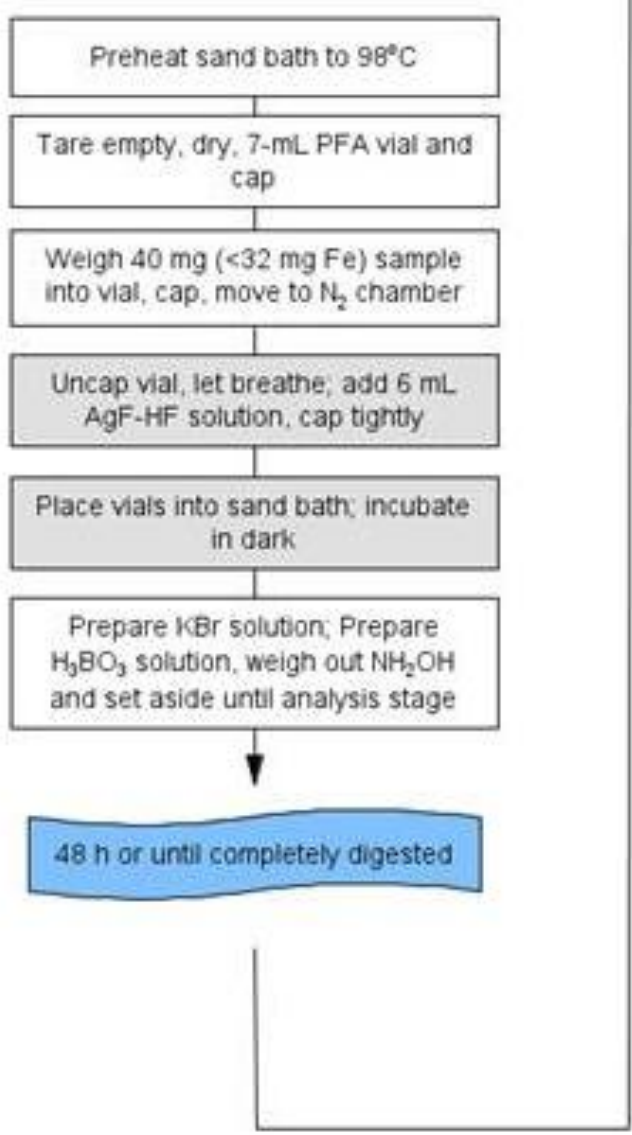

\section{Fe(II) ANALYSIS}

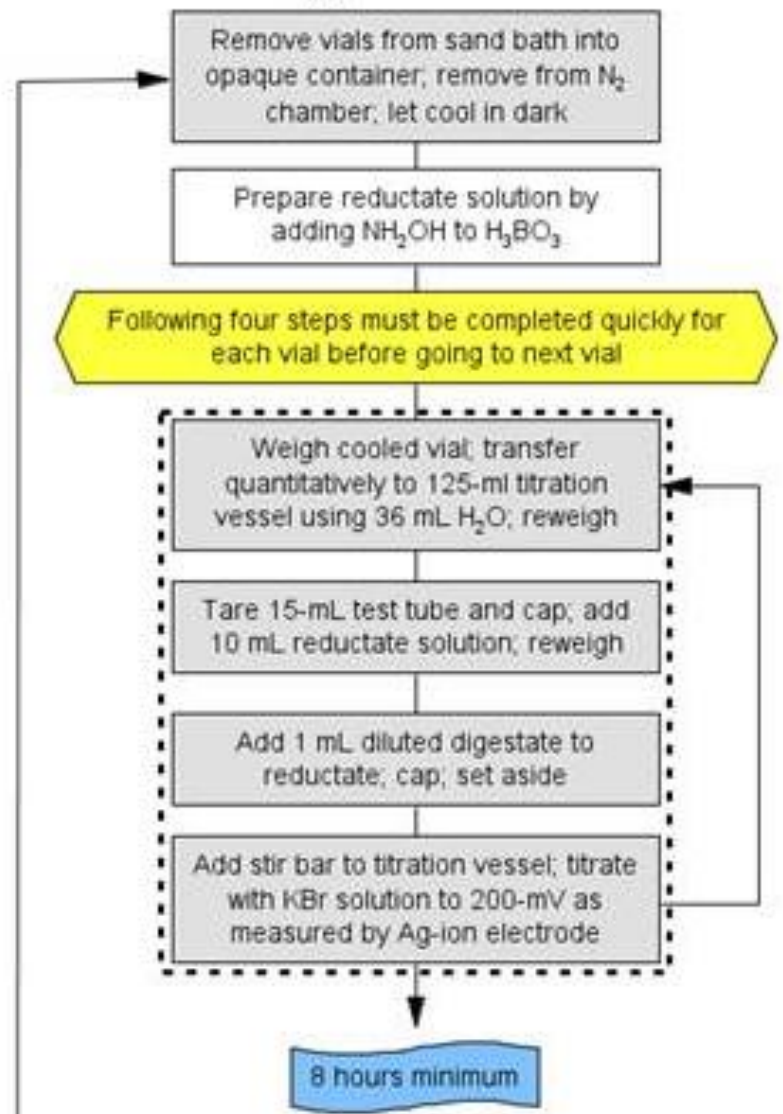

TOTAL Fe ANALYSIS

Prepare phen- $\mathrm{Na}_{3}$-citrate (analyzate) solution

Tare $15-\mathrm{mL}$ test tube and cap: add $10 \mathrm{~mL}$ analyzate solution, reweigh

After reductate has incubated at least $8 \mathrm{~h}$, add $1 \mathrm{~mL}$ reductate to analyzate solution, cap \& reweigh

Equalibrate analyzate $90 \mathrm{~min}$. measure absorbance at $510 \mathrm{~nm}$ 
$596 \quad$ Figure 2.

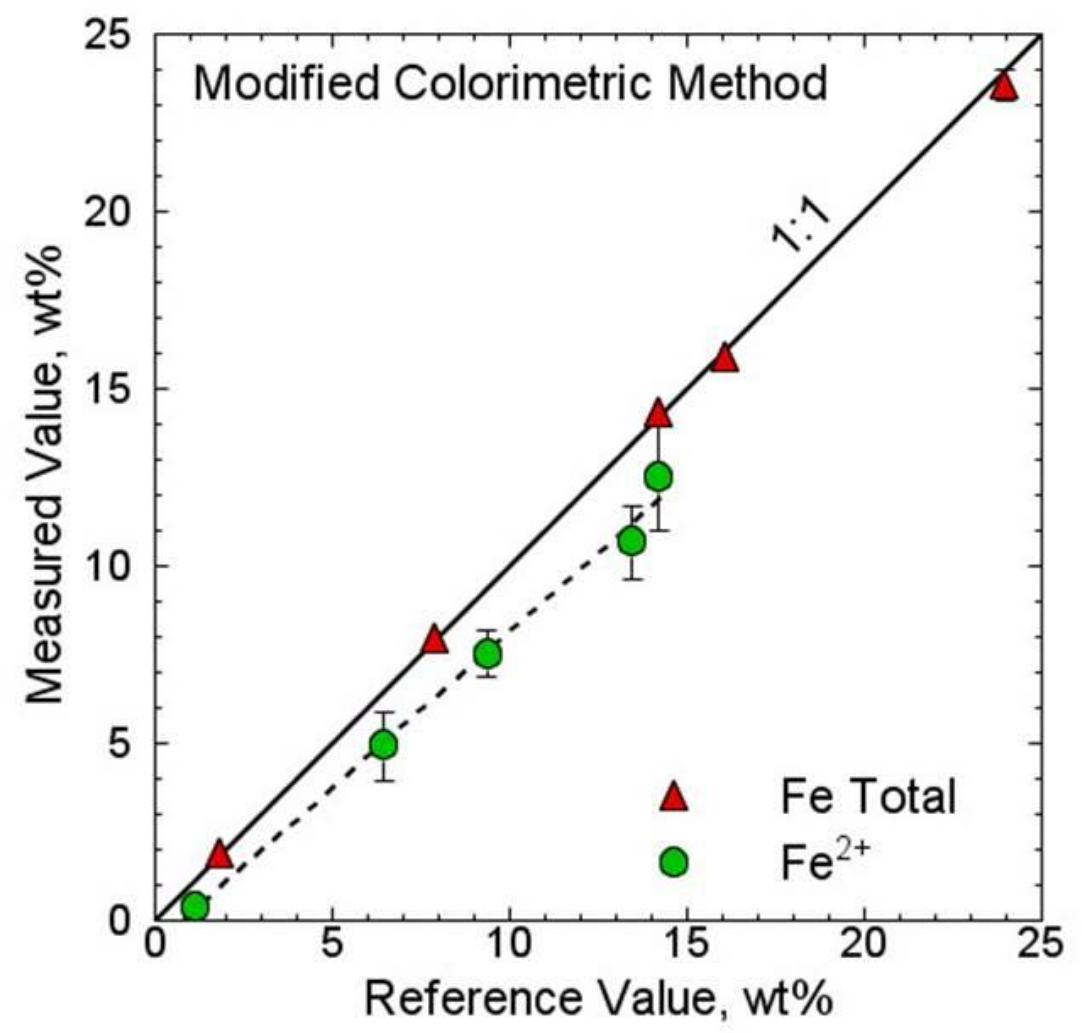

597

39

40

41

42

43

44

45

46

47

48

49

50

51

52

53

54

55

56

57

58

59

60

61

62

63 
$598 \quad$ Figure 3.

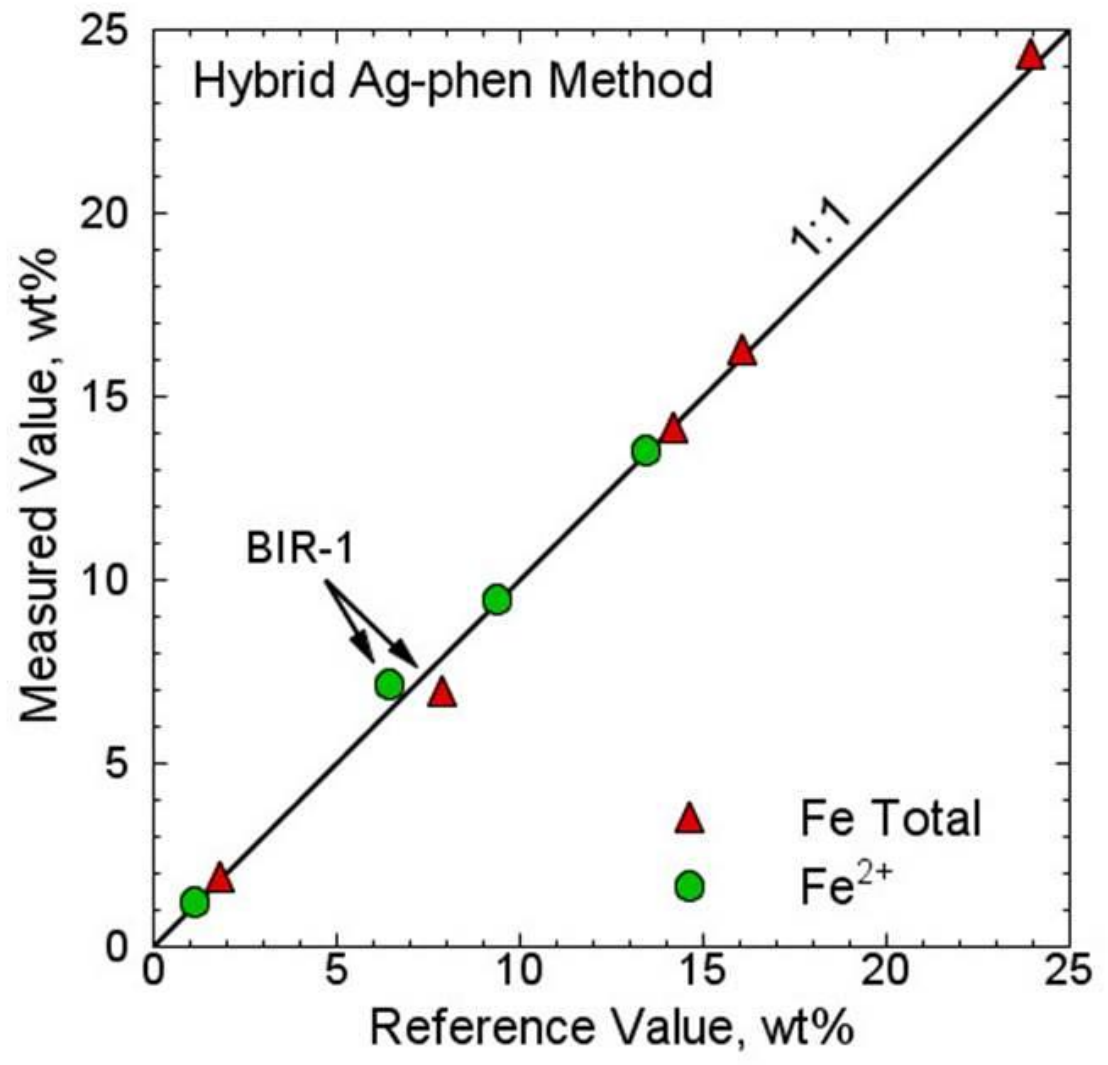

599

39

40

41

42

43

44

45

46

47

48

49

50

51

52

53

54

55

56

57

58

59

60

61

62

63

64

65 
$600 \quad$ Figure 4.

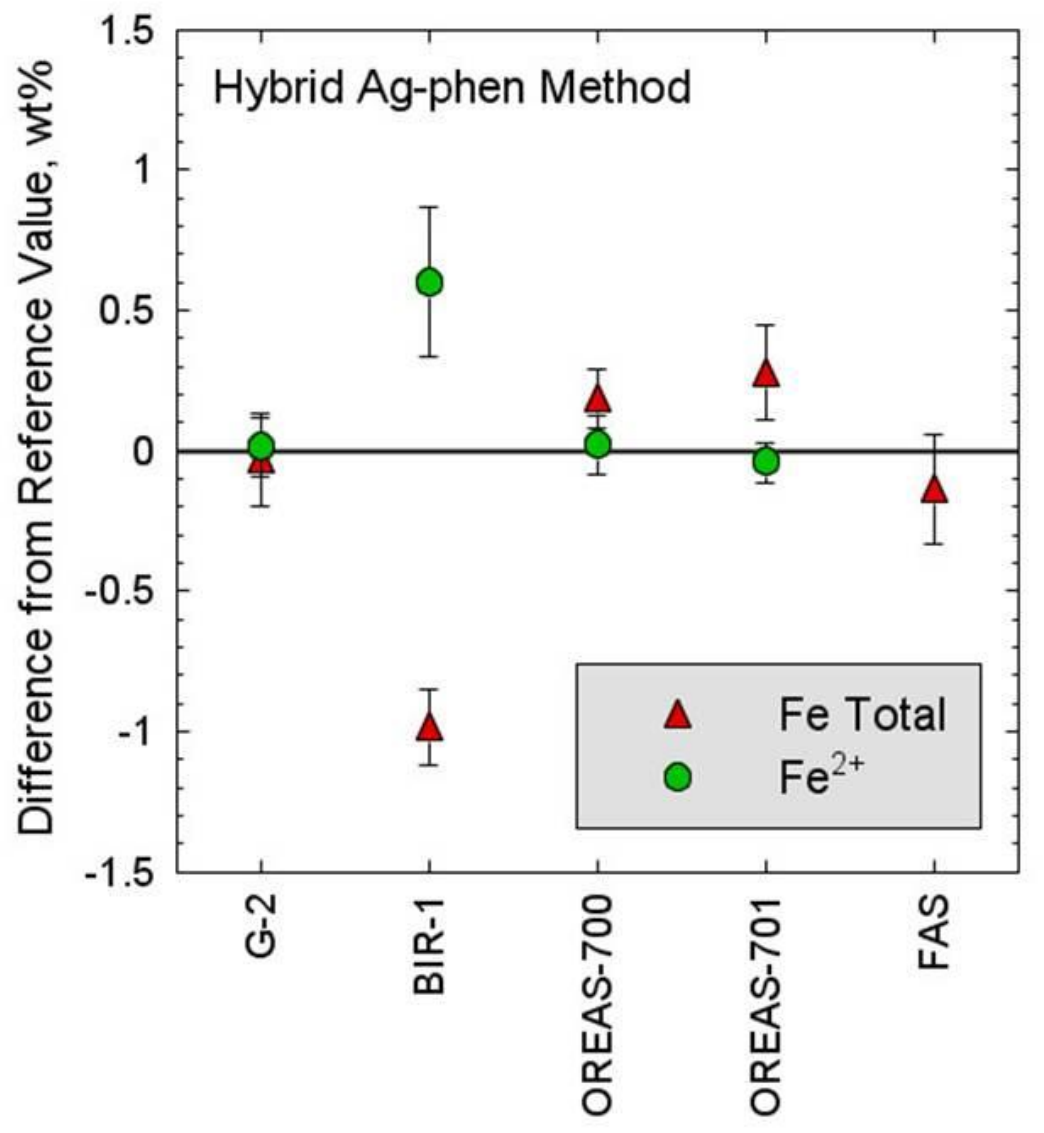

601

39

40

41

42

43

44

45

46

47

48

49

50

51

52

53

54

55

56

57

58

59

60

61

62

63

64

65 


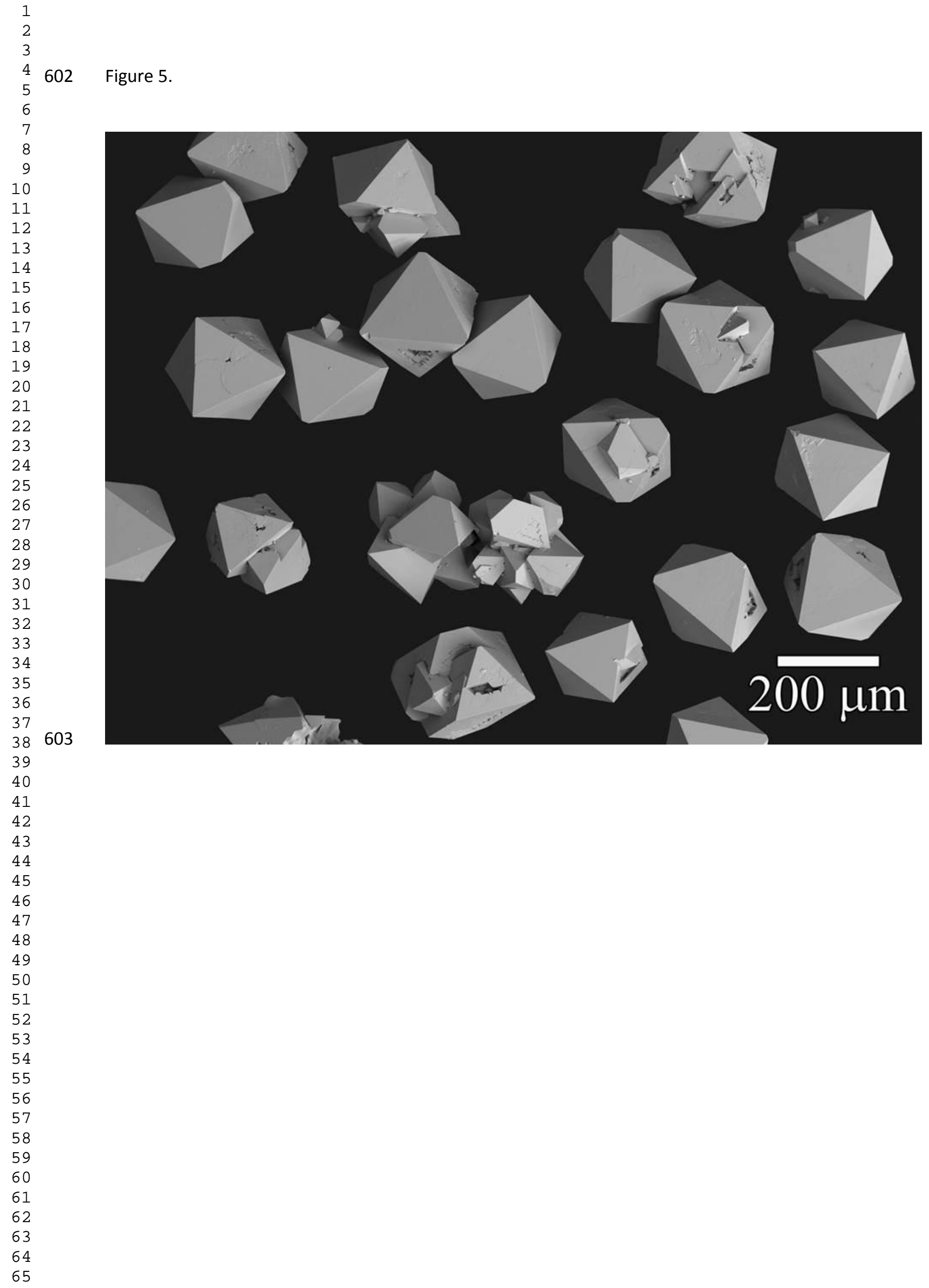

